\title{
OтоLоgY
}

\section{The short- and long-term adverse effects of FGF-2 on tympanic membrane perforations}

\author{
Gli effetti avversi di FGF-2 nelle perforazioni della membrana timpanica
}

\author{
L. ZHENG-CAl', L. ZI-HAN² \\ ${ }^{1}$ Department of Otolaryngology, the affiliated Yiwu Hospital of Wenzhou Medical University, Yiwu City, Zhejiang \\ Provice, China; ${ }^{2}$ Department of Clinical Medicine, Xinxiang Medical University, Xinxiang City, Henan Provice, China
}

\begin{abstract}
SUMMARY
The objective of this study was to investigate the short- and long-term adverse effects of fibroblast growth factor- 2 treatment of tympanic membrane perforations. A total of 134 patients with traumatic tympanic membrane perforations were randomly divided into two groups: an observational group and a fibroblast growth factor- 2 treatment group. The closure rate, closure time and principal side-effects were compared between the groups at 6 and 12 months. At 6 months, 131 patients were examined to determine healing outcomes and short-term side-effects. The total closure rate differed significantly between the fibroblast growth factor- 2 and observational groups ( $95.5 \%$ vs 73.4 , $\mathrm{p}<0.01)$. The fibroblast growth factor-treated group exhibited a significantly shorter closure time than the observational group $(11.9 \pm 3.1$ days $v s 52.6 \pm 18.1$ days, $\mathrm{p}=0.00$ ). Three patients with secondary otitis media with effusion, and three with reperforations, were noted in the fibroblast growth factor-2 group. We additionally performed long-term follow-up on $89.1 \%$ of the patients in the observational group and $92.5 \%$ of the patients in the fibroblast growth factor- 2 group; follow-up was performed $16-42$ months after perforation closure. Only a small perforation of the pars flaccida developed in the fibroblast growth factor- 2 group. No middle ear cholesteatoma was noted in either group. This study suggests that the topical application of fibroblast growth factor-2 to human traumatic tympanic membranes is safe. Otorrhoea was the most common short-term side-effect; other less common side-effects included otitis media with effusion and reperforation. No serious long-term side-effects were found.
\end{abstract}

KEY WORDS: Fibroblast growth factor-2 • Tympanic membrane regeneration • Side-effects $\bullet$ Reperforation

\section{RIASSUNTO}

L'obiettivo di questo studio è stato quello di valutare gli effetti avversi del trattamento con fattore di crescita dei fibroblasti 2 (FGF-2) delle perforazioni della membrana timpanica. 134 pazienti sono stati suddivisi in maniera randomizzata in due gruppi: un gruppo di controllo, sottoposto semplicemente ad osservazione clinica, ed un gruppo trattato con FGF-2. Sono stati quindi comparati tra i due gruppi $i$ tassi di chiusura, i tempi di chiusura, e gli effetti avversi, a 6 e 12 mesi. A 6 mesi, sono stati valutati 131 pazienti. Il tasso di chiusura totale è stato significativamente diverso tra il gruppo trattato con FGF-2 e il gruppo di controllo $(95,5 \%$ e 73,4\% rispettivamente, p < 0,01). Inoltre il gruppo sottoposto a trattamento con FGF-2 ha mostrato dei tempi di chiusura significativamente più brevi rispetto al gruppo di controllo (11,9 \pm 3,1 giorni contro 52,6 $\pm 18,1$ giorni, $p=0$,00. Nel gruppo trattato con FGF-2 sono stati registrati due casi di otite media effusive secondaria, e tre casi di riperforazione. Inoltre, è stato aggiunto un ulteriore follow-up nell'89,1\% dei pazienti appartenenti al gruppo di controllo, e nel 92,5\% dei pazienti trattati con FGF-2. Tale follow-up è stato eseguito tra 16 e 42 mesi dopo la chiusura della perforazione. Nei pazienti trattati con FGF-2 si è verificata solo una perforazione della pars flaccida della membrane timpanica. In entrambi i gruppi non sono stati segnalati casi di colesteatoma. Questo studio suggerisce che l'applicazione topica di FGF-2 sulle membrane timpaniche dannegggiate da un trauma è sicura. L'otorrea è stato il più comune effetto avverso a breve termine. Altri effetti a breve termine, meno comuni, sono stati l'otite media effusive e la riperforazione. Non stati riportati gravi effetti collaterali a lungo termine.

PAROLE CHIAVE: FGF-2 • Rigenerazione della membrana timpanica $\bullet$ Effetti collaterali $\bullet$ Riperforazione

Acta Otorhinolaryngol Ital 2018;38:264-272

\section{Introduction}

Fibroblast growth factor-2 (FGF-2) is a polypeptide mitogen that stimulates the proliferation of epidermal and connective tissue cells ${ }^{1}$. FGF-2 has been used to repair clinical and experimental tympanic membrane perforations (TMPs) ${ }^{2-6}$. Clinical studies have shown that topical application of FGF-2 significantly improves the closure rate and shortens the closure time of human traumatic 
TMPs ${ }^{478}$. The topical application of FGF-2 also showed a higher success rate for the repair of human chronic TMPs, thus providing an alternative to conventional myringoplasty ${ }^{359}$. However, the side-effects and safety of FGF-2 remain controversial. FGF-2 treatment of TMPs has not been widely adopted worldwide. Although some scholars previously undertook a series of clinical studies, the short- and long-term side-effects of FGF-2 on TMPs have not been not fully addressed. In addition, previous studies focused on traumatic TMPs without a history of middle ear disease and myringosclerosi ${ }^{478}$.

Most studies have suggested that FGF-2 is not ototoxic to the middle or inner ear, and does not cause sensorineural hearing loss ${ }^{2-6} 1011$. However, a few studies found that topical application of FGF-2 facilitated the proliferation of epithelial keratinocytes, causing short-term hyperplasia of the external auditory canal (EAC) and myringitis, and long-term cholesteatoma of the middle ear ${ }^{612-15}$. In addition, Laxarou et al. ${ }^{16}$ found that continuous application of FGF-2 inhibited the synthesis of collagen, in fact promoting collagen catabolism. Thus, apart from efficacy, the safety and side-effects of FGF-2 remain important clinical issues. The objective of this study was to investigate the short- and long-term side-effects of FGF-2 on human TMPs.

\section{Materials and methods}

The study was reviewed and approved by the institutional ethical review board of the Affiliated YiWu Hospital of Wenzhou Medical University, China, and was conducted in compliance with the Helsinki Declaration. Informed consent was obtained from all participants.

Study subjects were recruited from consecutive patients diagnosed with a traumatic TMP who visited the Department of Otorhinolaryngology of Affiliated YiWu Hospital (Wenzhou Medical University) between February 2010 and June 2013.

The inclusion criteria were as follows: (1) a traumatic TMP caused by a blunt injury, such as a physical blow (e.g., an open-handed slap, a fist strike, or a ball hit), or an explosive noise (e.g., the blast of firecrackers or fireworks); (2) a perforation size of at least one-quarter of the pars tensa; and (3) no middle ear infection, granulation tissue, or damage to the ossicular chain at the time of the hospital visit. A large perforation was defined as one exceeding $25 \%$ of the entire TM when viewed using ImageJ software (NIH, Bethesda, MD, USA) ${ }^{17}{ }^{18}$. The status of the residual tympanic membrane was divided into two categories: normal and pathological. A pathological membrane was defined as a residual membrane with local atro- phy or exhibiting deposition of calcified plaques, whereas a normal membrane was defined as a membrane lacking local atrophy or calcified plaques. Short-term side-effects were defined as those developing within 6 months of treatment; long-term side-effects were those developing 12 months after treatment.

The principal investigator, aided by a registered nurse, allocated patients to various treatments using simple random sampling. Specifically, consecutive subjects who met the inclusion criteria and signed the consent form were assigned random numbers generated by the SPSS for Windows software package (version 19.0; SPSS, Inc., Chicago, IL, USA) that allocated them to one of the FGF2 or observational groups.

\section{Technical methods}

Observational group. The residual tympanic membrane of patients in this group received no intervention, but underwent regular follow-up.

FGF-2 group. The external auditory canal (EAC) was cleaned with a cotton bud soaked in povidone/iodine solution at the time of the first visit. The edge of the perforation was not approximated, and no scaffolding material was used. A bottle of recombinant bovine FGF-2 solution (21,000 IU/5 mL; Yi Sheng, Zhuhai City, China) was prescribed by a clinician with instructions for the patient to apply three drops (approximately $0.15 \mathrm{~mL}$ ) once daily to the eardrum at home. The treatment ear was kept in an upward position for at least $30 \mathrm{~min}$ after the application of the eardrops to ensure that the FGF-2 solution moistened the residual eardrum. The FGF-2 application time until complete perforation closure was either confirmed by the physician or taken to be 6 months.

\section{Short-term follow-up}

Follow-up was scheduled once weekly for all patients until perforation closure. The tympanic membrane was oto-endoscopically examined at every follow-up to assess the size of the perforation and the otorrhoea status. At 6 months after treatment, all patients (whether their perforations had closed or not) were followed-up to assess the surface morphology of the eardrum (with or without reperforations). Pure-tone audiograms were obtained with the aid of a GSI 10 audiometer (VIASYS Healthcare, Inc., Conshohocken, PA, USA) with the patients in a quiet room. Audiograms were obtained before treatment, at perforation closure, and at the final follow-up after FGF treatment. The Pure Tone Average 4 (PTA4) air conduction threshold at $0.5,1,2$, and $4 \mathrm{kHz}$ was used to obtain the pure-tone average. Computed tomography (CT) of the temporal bone for perforations secondary to otorrhoea 
was performed at perforation closure, while CT was not performed for perforations that failed to close. CT was planned to be repeated at 1-3 months after the first CT scan if it revealed abnormal imaging results in the middle ear.

\section{Long-term follow-up}

Follow-up was scheduled at 12 months after perforation closure. We oto-endoscopically evaluated the surface morphology of healed eardrums. A CT scan of the temporal bone was performed to determine the cholesteatoma status of the middle ear in patients exhibiting atrophy of the eardrum or perforation of the pars flaccida.

\section{Statistical analysis}

Power Analysis and Sample Size software (version 11.0; NCSS, Kaysville, UT, USA) was used to estimate the sample size required to provide a power of $80 \%$ and a type I error of $5 \%(\mathrm{a}=0.05)$. A $15 \%$ difference in closure rate between the treatment and observation groups was predicted. The closure rate of the observational and FGF-2 drops groups would thus be $80.0 \%$ and $95 \%$, respectively. Using these values, it was determined that 56 patients per group were required. Assuming a loss to follow-up of $10 \%$, the number of patients needed per group was increased to 62 , giving a total of at least 124 patients. All results are expressed as means \pm SDs or as percentages. Statistical analyses were performed using SPSS software (version 11.0; SPSS, Inc.). The paired $\chi^{2}$ test and the matched-pair t-test were used to compare closure rates and times, respectively. A p $<0.05$ was deemed to indicate statistical significance.

\section{Results}

\section{Short-term healing and auditory outcomes}

A total of 134 patients met the inclusion criteria and only 3 (in the observation group) were lost to follow-up. Thus, 131 patients were finally analysed for short-term sideeffects. Of these, 64 were in the observational group and 67 in the FGF-2 group (Fig. 1). The demographic data of the two groups are shown in Table I. There was no statistically significant between-group difference in terms of age, sex, cause of injury, duration of injury, status of the residual tympanic membrane, side of ear, or hearing level. The healing outcomes of the two groups are shown in Table II. The total closure rate was significantly different between the FGF-2 and observational groups $(95.5 \%$ vs $\left.73.4, \mathrm{X}^{2}=12.34, \mathrm{p}<0.01\right)$. The FGF-treated group had a significantly shorter closure time than the observational

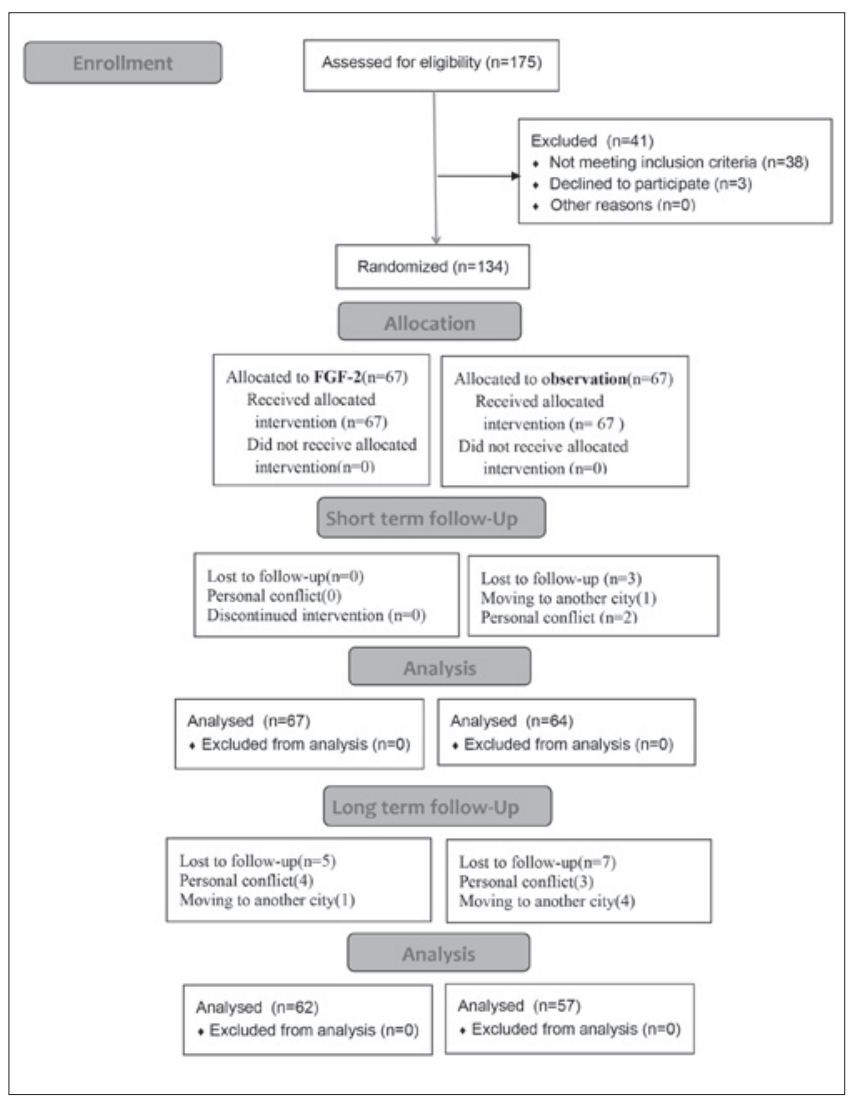

Fig. 1. Enrollment, randomization, and follow-up of the study participants.

group $(11.9 \pm 3.1$ days $v s 52.6 \pm 18.1$ days, $\mathrm{p}<0.01)$. Of the 64 patients with perforation closure in the FGF-2 group, 58 required a bottle of FGF-2 solution, and two bottles of FGF-2 solution were prescribed for 6 patients. The price of a bottle of FGF-2 solution was approximately $\$ 3.10$.

Table II shows that the closure rate was not significantly different between normal and pathological residual tympanic membranes in the FGF-2 (98.1\% vs 86.7\%, $\left.\mathrm{X}^{2}=1.38, \mathrm{p}>0.05\right)$ or observational groups $(76.9 \% \mathrm{vs}$ $\left.58.3 \%, X^{2}=0.91, p>0.05\right)$. The mean closure times of normal and pathological residual tympanic membranes did differ significantly $(\mathrm{p}<0.01)$ between groups. In addition, the closure rate did differ significantly between the FGF-2 and observational groups for either normal residual tympanic membrane $\left(98.1 \%\right.$ vs $76.9 \%, \mathrm{X}^{2}=10.64$, $\mathrm{p}<0.01)$. However, the closure rate did not differ significantly between the FGF-2 and observational groups for pathological residual tympanic membranes $(86.7 \% \mathrm{vs}$ $58.3 \%, \mathrm{p}=0.09)$. The mean closure times differed significantly between the FGF-2 and observational groups for both the normal and pathological residual tympanic 
Table I. Demographic data for patients who underwent short-term follow-up in each group.

\begin{tabular}{lccc} 
& FGF-2 group & p-value \\
& Observation group & 67 & $0.532 \mathrm{a}$ \\
Sex (male : female) & 64 & $25: 42$ & $0.68 \mathrm{~b}$ \\
Age, years & $37.4 \pm 5.1$ & $40: 4 \pm 6.7$ & $0.813 \mathrm{a}$ \\
Ear (left : right) & $42: 20$ & $3: 64$ & $0.568 \mathrm{a}$ \\
The cause of injury (B : E) & $5: 59$ & $6.4 \pm 2.8$ & $0.482 \mathrm{~b}$ \\
The duration of injury, days & $3.6 \pm 4.1$ & $52: 15$ & $0.715 \mathrm{a}$ \\
Residual TM (normal : pathology) & $52: 12$ & $29.1 \pm 4.3$ & $0.818 \mathrm{~b}$ \\
Hearing level & $28.6 \pm 5.3$ & \\
\hline
\end{tabular}

$p<0.05$ was considered statistically significant; $a=\chi^{2}$ test; $b=t$ test; $B=$ blunt injury; $E=$ explosion injury.

Table II. The short-term healing outcome and side-effects in each group.

\begin{tabular}{|c|c|c|c|c|c|c|c|c|}
\hline & & \multirow[t]{2}{*}{$\mathrm{N}$} & \multicolumn{2}{|c|}{ Healing outcome } & \multicolumn{4}{|c|}{ Side-effects } \\
\hline & & & $\begin{array}{c}\text { Closure rate, } \\
\text { n. }(\%)\end{array}$ & $\begin{array}{c}\text { Closure time, } \\
\text { days }\end{array}$ & $\begin{array}{l}\text { Purulent } \\
\text { otorrhoea }\end{array}$ & Pseudomembrane & $\begin{array}{l}\text { Otitis media } \\
\text { effusion }\end{array}$ & Reperforation \\
\hline \multirow[t]{2}{*}{ Observation group } & Normal residual TM & 52 & 40 (76.9\%) & $47.1 \pm 15.8$ & 4 & 2 & 0 & 0 \\
\hline & Pathologic residual TM & 12 & $7(58.3 \%)$ & $56.6 \pm 19.2$ & 3 & 0 & 0 & 0 \\
\hline \multirow[t]{2}{*}{ FGF-2 group } & Normal residual TM & 52 & $51(98.1 \%)$ & $10.1 \pm 4.6$ & 11 & 0 & 3 & 0 \\
\hline & Pathologic residual TM & 15 & $13(86.7 \%)$ & $19.1 \pm 7.3$ & 3 & 0 & 0 & 3 \\
\hline
\end{tabular}

membranes $(\mathrm{p}<0.01)$. The hearing improvement rates in the two groups did not differ significantly $(13.6 \pm 2.6 \mathrm{vs}$ $12.7 \pm 4.3 \mathrm{~dB}, \mathrm{p}=0.72$ ).

\section{Short-term side-effects}

In the FGF-2 group, there were $46(46 / 67,68.7 \%)$ patients whose residual tympanic membrane remained moist during treatment. However, 21 patients $(21 / 67,31.3 \%)$ did not comply with the protocol and applied a greater number of eardrops, resulting in a liquid residue in the EAC and middle ear causing otorrhoea. Of these patients, 14 (66.7\%) developed secondary purulent otorrhoea. Nevertheless, the rate of purulent otorrhoea among the two groups did not differ significantly $(14 / 67$ s $7 / 64, \mathrm{p}>0.05)$.

None of the seven patients in the observational group with secondary purulent otorrhoea achieved closure. In the FGF-2 group, of the 21 patients with otorrhoea, 7 patients with single otorrhoea and 12 patients $(12 / 14,85.7 \%)$ with purulent otorrhoea achieved complete closure, and the closure rate did not differ (19/21 vs 45/46, p > 0.05) between perforations with and without otorrhoea. Of the 19 closed perforations with otorrhoea, the CT scans of 13 patients revealed no abnormal imaging results in the middle ear, while the CT scans of 6 patients revealed softtissue shadows in the mastoid cavity at first examination. Of the six perforations with soft tissue in the middle ear cavity, the perforation size was more than $50 \%$ of the pars tensa in four perforations, and two patients had subtotal perforations. Nevertheless, CT was repeated, and soft-tissue shadows of the mastoid cavity disappeared after 1-2 months for six patients with abnormal imaging results on the first CT scan.

No severe side-effect (pain, severe vertigo, myringitis, or hyperkeratosis) was observed in either group; other side-effects are shown in Table II. A pseudomembrane was found in two patients in the observation group. In the FGF-2 group, of the 21 perforations with otorrhoea, three patients developed secondary otitis media with effusion (Fig. 2) and three reperforations were found. All of the reperforations were in residual tympanic membranes with myringosclerosis (Figs. 3, 4). Because the sample number of reperforations in the two groups was small, statistical analysis could not be performed.

\section{Long-term side-effects}

Long-term follow-up was performed on $57(57 / 64,89.1 \%)$ patients in the observational group and $62(62 / 67,92.5 \%)$ patients in the FGF-2 group at 16-42 months after perforation closure. The hearing improvement rates did not differ significantly between the two groups $(12.5 \pm 4.1 \mathrm{vs}$ $12.7 \pm 4.3 \mathrm{~dB}, \mathrm{p}=0.86$ ). All long-term side-effects are shown in Table III.

A small perforation of the pars flaccida was noted in one blast injury patient from the FGF-2 group (Fig. 5). 


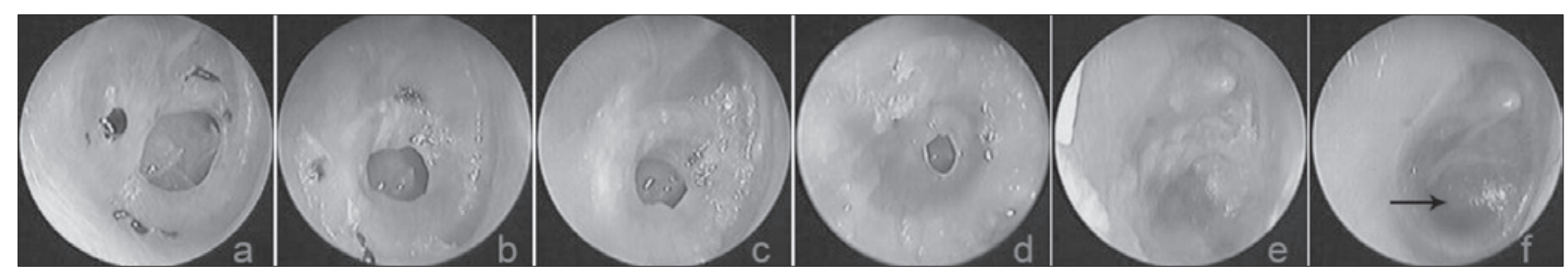

Fig. 2. The follow-up results at various time points after FGF-2 treatment: a) 10th day after perforation; b-f) 4 days, 8 days, 11 days, 15 days and 22 days after treatment, respectively ( $\rightarrow$ indicates otitis media effusion).
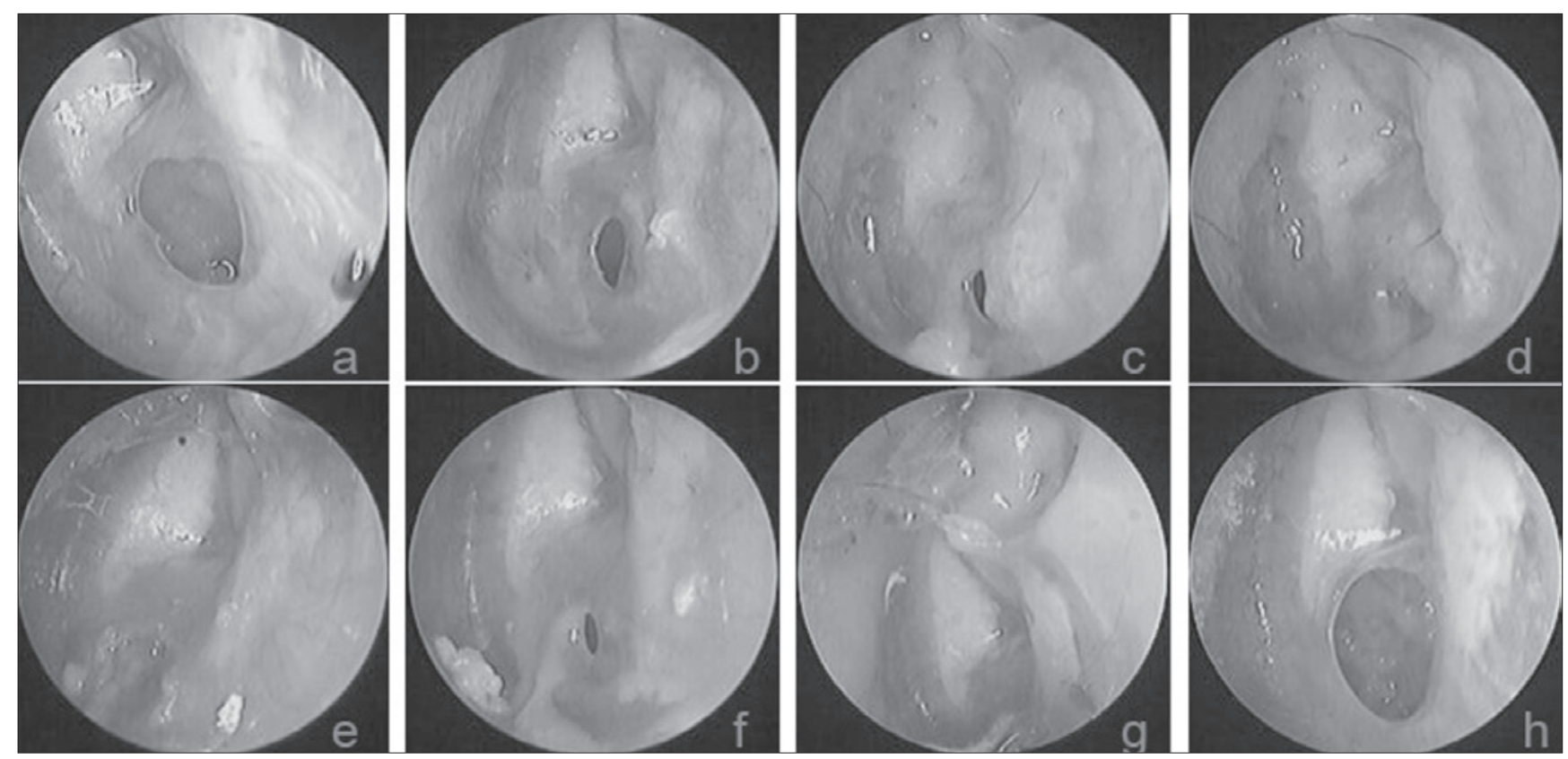

Fig. 3. The follow-up results at various time points after FGF-2 treatment: a) 20 days after perforation; b-g) 1 week, 2 weeks, 3 weeks, 4 weeks, 5 weeks, 8 weeks; and h) 26 months after treatment, respectively.

However, reperforation occurred in two patients with a pseudomembrane in the observation group. A pseudomembrane is different from an atrophic eardrum; it is a crust-like substance without the epithelial and fibrous layers of the eardrum (Fig. 6). An atrophic eardrum includes only the epithelial layer, without the fibrous layer of the eardrum. Atrophy of the healed eardrum was evident in $22(22 / 57,38.6 \%)$ patients in the observational group and $18(18 / 62,29.0 \%)$ patients in the FGF-2 group; this difference was not significant $\left(\mathrm{X}^{2}=1.22, \mathrm{p}>0.05\right)$. $\mathrm{CT}$ revealed no middle ear cholesteatoma in 40 patients with atrophic eardrums or a small perforation of the pars flaccida in the two groups.

\section{Discussion}

The effectiveness of FGF-2 used to treat TMP has been well-demonstrated both clinically and experimentally ${ }^{1-9}$. Application of FGF-2 alone or FGF-2 combined with patching, significantly improved TMP closure rates and shortened closure times ${ }^{34618}$. This study verified these findings. However, the side-effects of FGF2 on human TMPs remain incompletely understood. Otorrhoea was a common short-term side-effect of the FGF-2 treatment of traumatic TMPs in this study. Twenty-one patients $(21 / 67,31.3 \%)$ developed secondary otorrhoea, mainly caused by failure of the patient to abide by the study protocol. These patients applied a greater number of FGF-2 solution eardrops, resulting in an increased liquid environment in the EAC and middle ear. Nevertheless, the rate of purulent otorrhoea between the FGF-2 and observational groups did not differ significantly (14/67vs $9 / 64, p>0.05)$. None of the 7 patients in the observational group with secondary purulent otorrhoea was found 


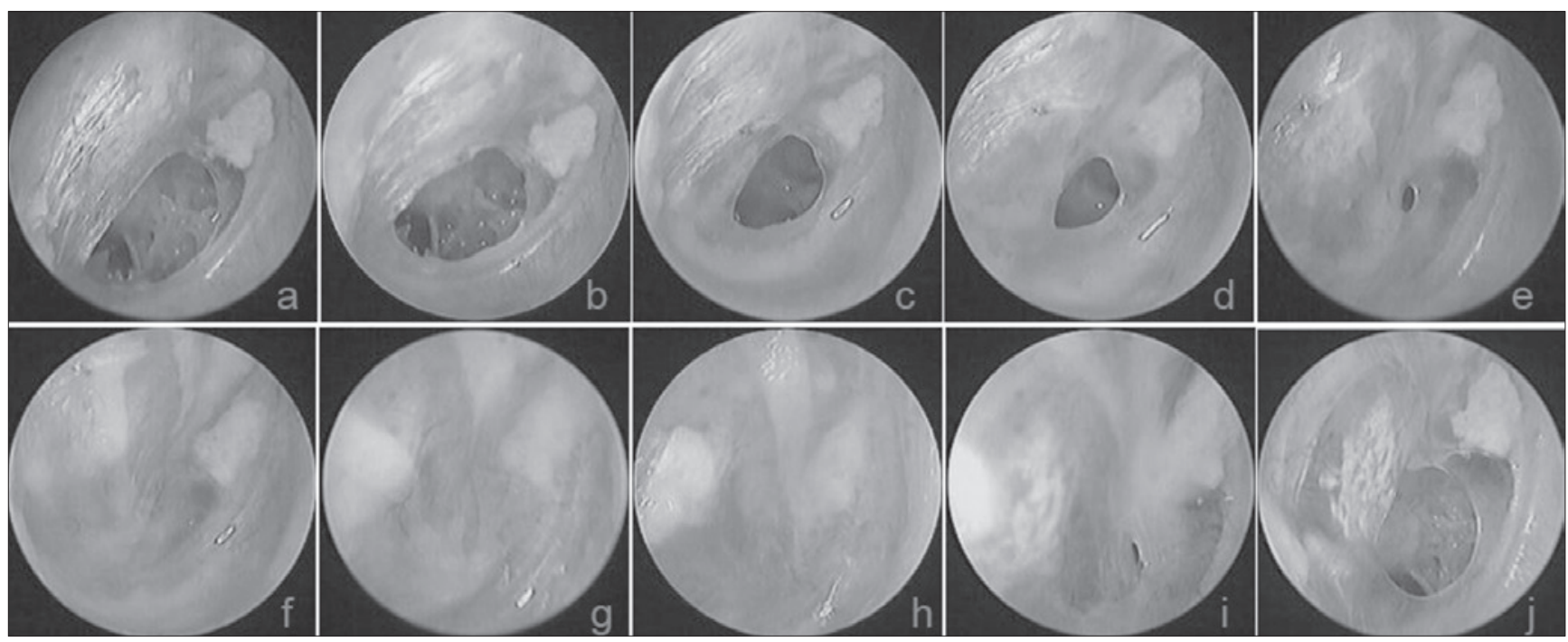

Fig. 4. The follow-up results at various time points after FGF-2 treatment: a) $3^{\text {rd }}$ day after perforation; $\mathbf{b}$-j) 3 days, 7 days, 10 days, 14 days, 16 days, 20 days, 25 days, 30 days and 6 months after treatment, respectively.

Table III. The long-term side-effects in each group.

\begin{tabular}{lccccc} 
& & N. & Reperforation & Atrophic eardrum & Cholesteatoma \\
Observation group & Normal residual TM & 48 & 2 & 13 & 0 \\
\multirow{2}{*}{ FGF-2 group } & Pathologic residual TM & 9 & 0 & 9 & 0 \\
& Normal residual TM & 49 & 1 & 5 & 0 \\
\hline
\end{tabular}

to have achieved closure, whereas 12 of 14 such patients $(85.7 \%)$ in the FGF-2 group attained complete closure. A previous study showed that infections of the middle ear adversely affected the spontaneous healing of traumatic TMPs; however, the topical application of FGF-2 could overcome the bacteria-induced inhibition of healing ${ }^{19}$. The prescription of FGF-2 to treat inflamed tissue enhanced leukocyte recruitment and expression of the endothelial cell adhesion molecule, indirectly enhancing the antimicrobial activity of the ear ${ }^{2021}$.

In this study, 3 patients developed secondary otitis media with effusion 3-10 days after closure of the perforation among 21 patients with otorrhoea. It is unclear whether the development of otitis media with effusion was associated with FGF-2. However, a large amount of FGF-2 solution in the middle ear may facilitate hyperplasia of the granulation tissue of the mucus membrane of the middle ear and Eustachian tube, thus obstructing the tube and inducing otitis media effusion.

Hakuba et al. ${ }^{39}$ reported that the rate of reperforation of FGF-2-treated chronic TMPs was $18 \%$ after one year. In this study, during 6 months of short-term follow-up, the reperforation rate was found to be much lower. Reperforation occurred in 3 patients $(3 / 67,4.48 \%)$ with myringosclerosis; none of the normal membranes suffered reperforation in the FGF-2 group, and no reperforations were found in the observation group. During long-term follow-up, two patients with a pseudomembrane experienced reperforation in the observation group. A small perforation of the pars flaccida was noted in one blast injury patient from the FGF-2 group. However, the original position of the pars tensa did not show reperforation. Because the sample number of reperforations in the two groups was small, statistical analysis could not be performed. The long-term reperforation in two patients with a pseudomembrane in the observation group could have been due to the fact that the pseudomembrane gradually fell off over time. The cause of reperforation in the shortterm is unclear in the FGF-2 group and requires further study. Perforation of the pars flaccida in the long-term in the FGF-2 group could be due to the fact that excessive FGF-2 solution facilitated hyperplasia of the granulation tissue of the mucus membranes of all of the tympanic cavity, tympanic antrum, aditus ad antrum and Eustachian 

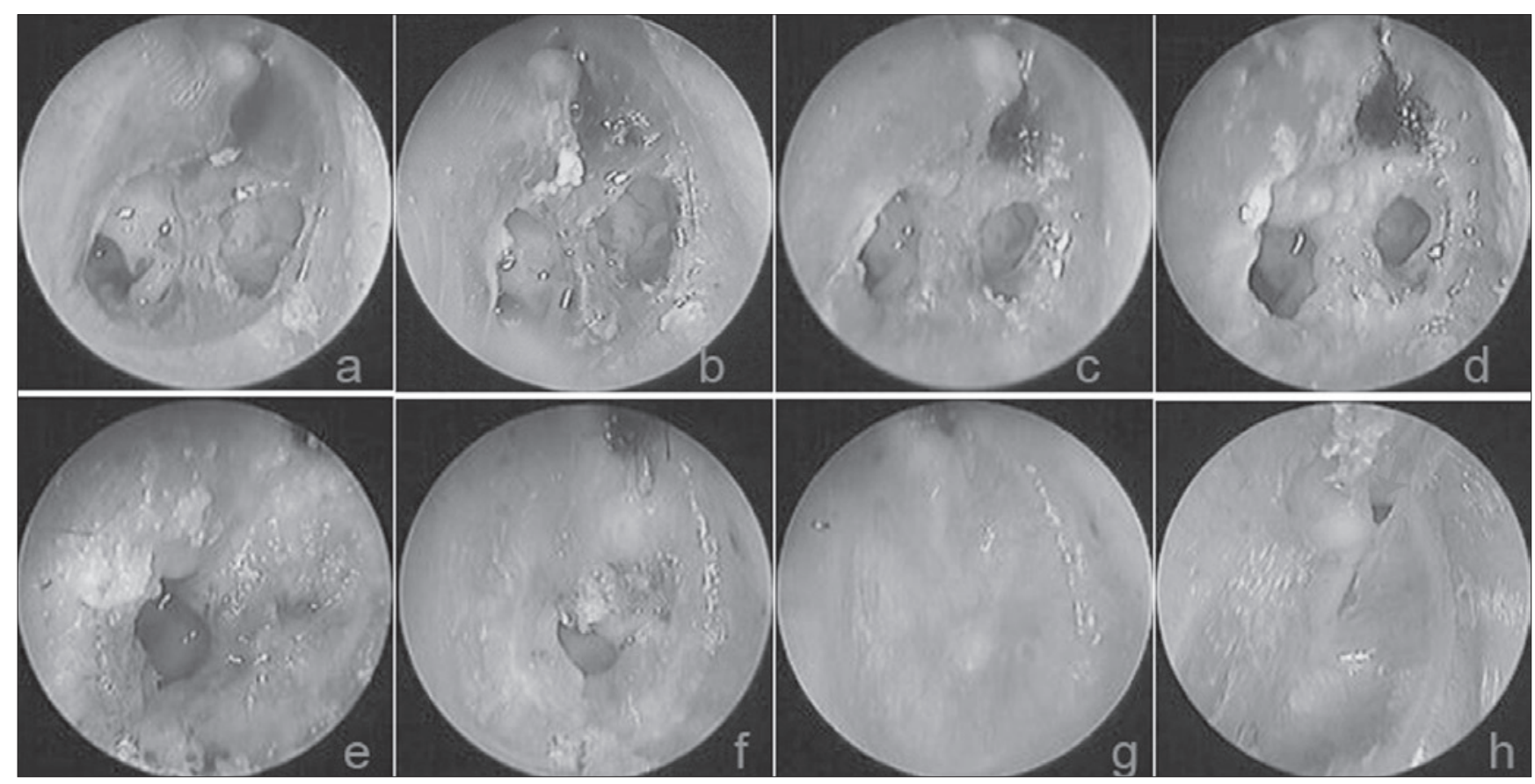

Fig. 5. The follow-up results at various time points after FGF-2 treatment: a) $1^{\text {st }}$ day after perforation; $\left.\mathbf{b}-\mathrm{h}\right) 1$ day, 3 days, 5 days, 8 days, 11 days, 14 days and 23 months after treatment, respectively ( $\rightarrow$ indicates a small perforation in the pars flaccida).
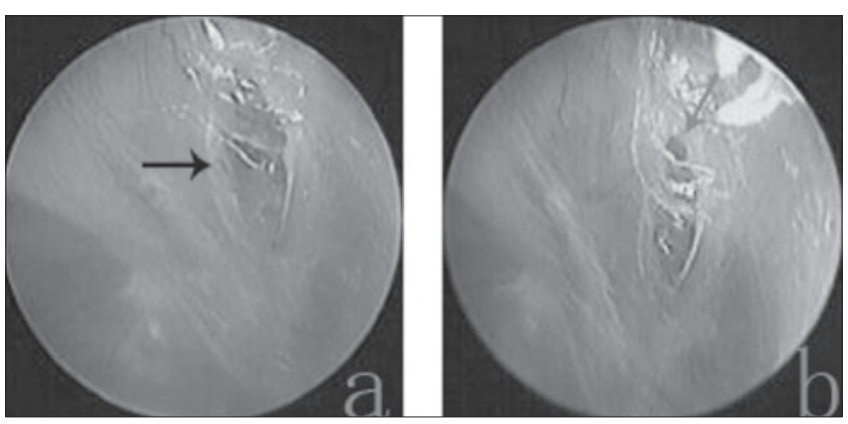

Fig. 6. a) A crust-like substance formed the pseudomembrane and closed the perforation (black arrow indicates the pseudomembrane); b) The partial pseudomembrane fell off and formed a reperforation (grey arrow indicates the perforation).

tube, thereby interfering with gas exchange between the Eustachian tube, mastoid sinus and tympanic cavity. Ultimately, a retraction pocket formed and the pars flaccida became reperforated over time.

One previous study found that FGF-2 was unlikely to be ototoxic ${ }^{10}$. The cited work showed that auditory findings did not change either short- or long-term after perforation closure. Kase et al. ${ }^{10}$ found that topical FGF-2 applied to the middle ear did not significantly reduce the endocochlear DC potential (EP), damage the stapes, or trigger perilymph leakage. The gradual toxic effect of FGF-2 could affect the high-frequency level. Unfortunately, audiometric data at the high-frequency level were not recorded in this study. Nevertheless, other studies have suggested that topical FGF-2 does not trigger degenerative changes in structures of the organ of Corti and is not ototoxic ${ }^{822}$. In contrast, several interesting reports have shown that FGF2 protects sensory hair cells ${ }^{23} 24$.

The functional outcomes of the eardrum must be considered when analysing healing after FGF-2 treatment. The tympanic membrane is normally a three-layered structure featuring an epithelial layer, a fibrous layer and a mucus layer. Absence of the fibrous layer causes atrophy eardrum. Over the long-term follow-up period, atrophic eardrums were found in $18(18 / 62,29.0 \%)$ patients in the FGF-2 group and $22(22 / 57,38.6 \%)$ patients in the observation group. Thus, atrophy is not unique to patients treated with FGF-2 ${ }^{16}$. A previous study confirmed that spontaneous healing of the tympanic membrane was characterized by healing of only two of the layers; the fibrous layer was lacking ${ }^{2526}$. Theoretically, topical application of FGF-2 induced fibroblast proliferation and facilitated hyperplasia of the fibrous layer; thick tympanic membranes were formed 3927 . Atrophic eardrums should not occur after FGF-2 treatment. The reason why FGF-2 treatment caused eardrum atrophy thus requires further study. A previous study showed that prolonged application of FGF-2 inhibited collagen synthesis and promoted collagen ca- 
tabolism ${ }^{16}$. Inhibition of collagen deposition affords a minimal benefit, and might even be detrimental, causing atrophy of the eardrum and reperforation ${ }^{1622}$. In addition, the molecular environment of a chronic wound may impair the effectiveness by which growth factors stimulate healing and de novo vascularisation 2829 .

Whether the topical application of FGF-2 may trigger cholesteatoma of the middle ear remains controversial. Some studies have suggested that FGF-2 may induce keratinocyte proliferation in the epithelium of the eardrum. Middle ear cholesteatoma may then develop via ingrowth of the epidermis through the hyperplastic connective tissue of the lamina propria ${ }^{12}{ }^{13}$. However, Friedman et al.13 found that the risk of cholesteatoma formation after shortterm use of FGF-2 to treat acute perforations was minimal in an animal model. In our study, CT revealed no middle ear cholesteatoma formation in patients with an atrophic eardrum and reperforation.

Hakuba et al. ${ }^{15}$ reported a 5\% incidence of cholesteatoma when FGF-2 was used to treat chronic TMPs. However, cholesteatoma formation is not confined to patients treated with FGF-2. Sridhara et al. ${ }^{30}$ reported that the incidence of cholesteatoma was $9 \%$ in patients with traumatic TMPs treated by tympanoplasty. Kronenberg et al., in two reports, found that the incidences of cholesteatoma were $7.6 \%$ and $4.8 \%$ during spontaneous healing of traumatic TMPs ${ }^{31}{ }^{32}$. Thus, cholesteatoma formation in the middle ear could be not associated with FGF-2 per se, but rather with the nature and wet environment of the middle ear. Previous studies showed that a wet environment in the middle ear may induce cholesteatoma formation ${ }^{33} 34$. Our recent clinical observations confirmed these findings ${ }^{35}$. In the present work, CT performed after perforation closure revealed soft tissue shadows of varying extent in the mastoid cavities in six patients, with subsequent gasification to form normal mastoid processes. We speculate that the soft tissue hyperplasia in the middle ear cavity was related to the size of the perforation rather than a greater number of eardrops. The perforation size was more than $50 \%$ of the pars tensa and subtotal in six patients. This fact is important because one may assume that the larger a perforation is, the greater the likelihood that the solution will enter the middle ear cavity and, consequently, the higher the possibility of a reaction in the middle ear mucosa.

A limitation of this study is that it was not a placebocontrolled study using saline. This would have allowed us to better understand the effect of a moist environment on eardrum healing. However, previous experimental studies showed that the topical application of saline did not aid eardrum healing. Second, assessment of the function of the Eustachian tube was not undertaken. This would be beneficial in order to analyse the side-effects of reperforation and atrophic eardrums. In addition, high-frequency audiometric data should be evaluated in future.

\section{Conclusions}

This study suggests that the topical application of FGF2 on human TMPs is safe. FGF-2 is simple, convenient and inexpensive (the price of a bottle of FGF-2 solution is \$3.10). However, regular follow-up is required. Clinicians should check and correct the number of FGF-2 solution bottles used by patients at each follow-up visit since the optimum amount of FGF-2 solution should keep the remnant eardrum moist each day and avoid the accumulation of solution in the middle ear. Otorrhoea was the most common short-term side-effect of FGF-2 treatment for a TMP, with other less common side-effects including otitis media with effusion and reperforation. No serious longterm side-effects were found.

\section{Acknowledgements}

This study was supported by the Science and Technology Agency of Zhejiang Province and Health \& Medicine Agency of Zhejiang Province, China (Grants \#2013C33176 and 2015KYB420).

\section{References}

1 Mondain M, Ryan A. Effect of basic fibroblast growth factor on normal tympanic membrane. Am J Otolaryngol 1994;15:344-50.

2 Kakigi A, Sawada S, Takeda T. The effects of basic fibroblast growth factor on postoperative mastoid cavity problems. Otol Neurotol 2005;26:333-6.

3 Hakuba N, Iwanaga M, Tanaka S, et al. Basic fibroblast growth factor combined with atelocollagen for closing chronic tympanic membrane perforations in 87 patients. Otol Neurotol 2010;31:118-21.

4 Lou Z, Wang Y. Evaluation of the optimum time for direct application of fibroblast growth factor to human traumatic tympanic membrane perforations. Growth Factors 2015;33:65-70.

5 Acharya AN, Coates H, Tavora-Vièira D, et al. A pilot study investigating basic fibroblast growth factor for the repair of chronic tympanic membrane perforations in pediatric patients. Int J Pediatr Otorhinolaryngol 2015;79:332-5.

6 Kanemaru S, Umeda H, Kitani Y, et al. Regenerative treatment for tympanic membrane perforation. Otol Neurotol 2011;32:1218-23.

7 Lou ZC, Wang YB. Healing outcomes of large (> 50\%) traumatic membrane perforations with inverted edges following no intervention, edge approximation and fibroblast growth factor application; a sequential allocation, three-armed trial. Clin Otolaryngol 2013;38:289-96. 
8 Lou Z. Healing large traumatic eardrum perforations in humans using fibroblast growth factor applied directly or via gelfoam. Otol Neurotol 2012;33:1553-7.

9 Hakuba N, Hato N, Okada M, et al. Preoperative factors affecting tympanic membrane regeneration therapy using an atelocollagen and basic fibroblast growth factor. JAMA Otolaryngol Head Neck Surg 2015;141:60-6.

10 Kase K, Iwanaga T, Terakado M, et al. Influence of topical application of basic fibroblast growth factor upon inner ear. Otolaryngol Head Neck Surg 2008;138:523-7.

11 Chauvin K, Bratton C, Parkins C. Healing large tympanic membrane perforations using hyaluronic acid, basic fibroblast growth factor, and epidermal growth factor. Otolaryngol Head Neck Surg 1999;121:43-7.

12 Mondain M, Ryan A. Effect of basic fibroblast growth factor on normal tympanic membrane. Am J Otolaryngol 1994;15:344-50.

13 Friedman NR, Wright CG, Pawlowski KS, et al. Effect of basic fibroblast growth factor on perforated chinchilla tympanic membranes. Ear Nose Throat J 1997;76:559-64.

14 Mondain M, Saffiedine S, Uziel A. Fibroblast growth factor improves the healing of experimental tympanic membrane perforations. Acta Otolaryngol 1991;111:337-41.

15 Hakuba N, Hato N, Omotehara Y, et al. Epithelial pearl formation following tympanic membrane regeneration therapy using an atelocollagen/silicone membrane and basic fibroblast growth factor: our experience from a retrospective study of one hundred sixteen patients. Clin Otolaryngol 2013;38:394-7.

16 Laxarou SA, Efron JE, Shaw T. Fibroblast growth factor inhibits wound collagen synthesis. Surg Forum 1989;40:627-9.

17 Saito H, Kazama Y, Yazawa Y. Simple maneuver for closing traumatic eardrum perforation by micropore strip tape patching. Am J Otol 1990;11:427-30.

18 Lou ZC, Tang YM, Yang J. A prospective study evaluating spontaneous healing of aetiology, size and type-different groups of traumatic tympanic membrane perforation. Clin Otolaryngol 2011;36:450-60.

19 Stenberg BD, Phillips LG, Hokanson JA, et al. Effect of bFGF on the inhibition of contraction caused by bacteria. J Surg Res 1991;50:47-50.

20 Zittermann SI, Issekutz AC. Basic fibroblast growth factor (bFGF, FGF-2) potentiates leukocyte recruitment to inflammation by enhancing endothelial adhesion molecule expression. Am J Pathol 2006;168:835-46.
$21 \mathrm{Hu}$ YF, Wu YJ. Effect of recombinant human basic fibroblast growth factor on acute inflammation in mice and rats. Acta Pharmacol Sin 2001;22:375-9.

22 Kato M, Jackler RK. Repair of chronic tympanic membrane perforations with fibroblast growth factor. Otolaryngol Head Neck Surg 1996;115:538-47.

23 Low W, Dazert S, Baird A, et al. Basic fibroblast growth factor (FGF2) protects rat cochlear hair cells in organotypical culture from aminoglycoside injury. J Cell Physiol 1996;167:443-50.

24 Zhai SQ, Wang DJ, Wang JL, et al. Basic fibroblast growth factor protects auditory neurons and hair cells from glutamate neurotoxicity and noise exposure. Acta Otolaryngol 2004;124:124-9.

25 Govaerts PJ, Jacob WA, Marquet J. Histological study of the thin replacement membrane of human tympanic membrane perforations. Acta Otolaryngol 1988;105:297-302.

26 Yamashita T. Histology of the tympanic perforation and the replacement membrane. Acta Otolaryngol 1985;100:66-71.

27 Hakuba N, Tabata Y, Hato N, et al. Gelatin hydrogel with basic fibroblast growth factor for tympanic membrane regeneration. Otol Neurotol 2014;35:540-4.

28 Okan D, Woo K, Ayello EA, et al. The role of moisture balance in wound healing. Adv Skin Wound Care 2007;20:39-53.

29 Vrabec JT, Schwaber MK, Davidson JM, et al. Evaluation of basic fibroblast growth factor in tympanic membrane repair. Laryngoscope 1994;104:1059-64.

30 Sridhara SK, Rivera A, Littlefield P. Tympanoplasty for blast-induced perforations: the Walter Reed experience. Otolaryngol Head Neck Surg 2013;148:103-7.

31 Kronenberg J, Ben-Shoshan J, Modan M, et al. Blast injury and cholesteatoma. Am J Otol 1988;9:127-30.

32 Kronenberg J, Ben-Shoshan J, Wolf M. Perforated tympanic membrane after blast injury. Am J Otol 1993;14:92-4.

33 Meyerhoff WL, Marple BF, Roland PS. Tympanic membrane, middle ear, and mastoid. In: Hearing Loss. New York: Thieme Medical Publishers, Inc.; 1997. pp. 155-94.

34 Winerman I, Man A, Segal S. Early repair of traumatic perforations of the tympanic membrane in children. Int J Pediatr Otorhinolaryngol 1982;4:23-7.

35 Lou ZC, Tang YM, Yang J. A prospective study evaluating spontaneous healing of aetiology, size, and type-different groups of traumatic tympanic membrane perforation. Clin Otolaryngol 2011;36:450-60. 